\title{
Letters
}

Website: www.bmj.com

Email: letters@bmj.com

\section{Hospital at home}

\section{Schemes evolve gradually}

EDITOR-In his editorial on hospital at home schemes Iliffe highlights the need for "descriptive studies of the organisational culture and practice of [such] innovative services" to supplement the findings of trials. ${ }^{1}$ In evaluating a local hospital at home scheme for orthopaedic patients ${ }^{2}$ we put our findings into context by obtaining the views of hospital and community based staff on the practicality and acceptability of such a service. ${ }^{3}$

At the outset the staff were ambivalent about the concept of early discharge. Although they were more positive about the concept once the service started, many remained negative about the practicality of running the service. Staffing and financial costs gave rise to particular concerns. Despite apprehension that general practitioners may face additional burdens, neither the reported studies ${ }^{45}$ nor our own findings support this. We can also confirm Iliffe's suggestion that length of stay was sometimes prolonged by delays in arranging social services support to enable seamless care on discharge.

Controlled trials generally use dedicated teams, but this scheme had occasionally to rely on locum cover for physiotherapists and occupational therapists, with consequences for patient throughput and, potentially, continuity of care. Staff turnover was unusually high, which could partly be explained by healthcare support workers using the scheme as a stepping stone to a clinical career. Such staffing features are not necessarily accounted for in economic analyses, which makes it even more difficult for providers to interpret the currently equivocal views on cost benefit.

There was some anxiety about awareness of the roles and responsibilities of each member of the team and about encroaching on other professionals' roles. The needs for suitable training and good communication systems were highlighted. The introduction of healthcare support workers spawned a training programme that is now used for ancillary staff throughout the trust. As the scheme has evolved, one team member has become responsible for coordinating discharges, a specific geriatrician has become involved, and the scheme has been integrated into a broader intermediate care programme. These measures alone cannot be expected to offset the challenges of operat- ing a multidisciplinary, multiagency service with interprofessional tensions. Regular monitoring via audit is needed. We echo Iliffe's call for further reporting of the organisational arrangements associated with hospital at home schemes, to support the development of such schemes and promote good practice.

Jane Sims Lecturer in primary health care sciences Elizabeth Rink Lecturer in primary health care sciences

Department of General Practice, St George's Hospital Medical School, London SW17 0RE erink@sghms.ac.uk

1 Iliffe S. Hospital at home: from red to amber? $B M$ 1998;316:1761-2. (13 June.)

2 Rink EM, Sims J, Walker R, Pickard L. Hospital care a home: an evaluation of a scheme for orthopaedic patient. Health and Social Care in the Community 1998;6:158-63.

Sims J, Rink EM, Walker R, Pickard L. The introduction of a hospital at home service: a staff perspective. I Interprofessional Care 1997:11:217-24.

4 Shepperd S, Harwood D, Jenkinson C, Gray A, Vessey M, Mhen P. Randomised controlled trial comparing hospal an . Rando with inpatient hospital caring hosplollow up of health outcomes. $B M J$ 1998;316: 1786-91. (13 June.)

5 Richards SH, Coast J, Gunnell DJ, Peters TJ, Pounsford J, Darlow M-A. Randomised controlled trial comparin effectiveness and acceptability of an early discharge, hospital at home scheme with acute hospital care. $B M$ 1998;316:1796-801. (13 June.)

\section{For people with severe mental illness,} results are encouraging

EDITOR-Iliffe raises several important points concerning the provision of hospital at home schemes as an alternative to inpatient care in the NHS. ${ }^{1}$ In particular, he highlights the current growth in the popularity of this approach despite the relative lack of evidence of its general applicability and cost effectiveness.

There are interesting parallels to be drawn in the field of mental health. Over the past few decades, Britain-in common with most other Western countries-has moved towards the provision of community based services for people with mental health problems. Mental health providers are now expected to offer a range of services, including residential care, day care, and home based care, with access to 24 hour provision of crisis care. ${ }^{2}$ The tendency towards more localised and flexible treatment approaches has included the development of intensive home support schemes with extended hours. The variety of intensive home support models that have been established all seem to share the aim of providing an alternative to hospital admission or facilitating early discharge for those in an acute phase of a severe mental illness.
The initial evidence to support these developments came largely from controlled studies in the United States, Canada, and Australia, later replicated in London. ${ }^{3}$ These studies showed that home based care could be as effective as inpatient treatment in improving clinical and social functioning, was cost effective, and was consistently preferred by patients and their carers. Recent evaluations of "real life" intensive mental health support teams, operating within the NHS, similarly suggest that this approach can prevent psychiatric admission for some people, can be cheaper than acute inpatient care, and can be just as clinically effective.

These results are encouraging, but some caution is required as there is little evidence to suggest that these benefits can be sustained and some indication that drawbacks may exist. ${ }^{5}$ More research is needed to identify the most appropriate client group for such treatment and to ascertain whether the benefits for patients can be maintained in the longer term and staff burnout avoided. This may also have implications for the ongoing cost effectiveness of such services.

Marie Cleary Research assistant in mental health Chris Pearson Research assistant in mental health Keith Lloyd Consultant psychiatrist Department of Mental Health, University of Exeter, Wonford House Hospital, Exeter EX2 5AF

1 Iliffe S. Hospital at home: from red to amber? $B M J$ 1998;316:1761-2. (13 June.)

2 Department of Health. The spectrum of care. Local services for people with mental health problems. London: $\mathrm{DoH}, 1996$.

3 Marks IM, Connolly J, Muijen M, Audini B, McNamee G, Lawrence RE. Home-based versus hospital-based care for people with serious mental illness. $B r \quad J$ Psych 1994;165:179-94

4 Minghella E, Ford R, Freeman T, Hoult J, McGlynn P, O'Halloran P. Open all hours. 24-hour response for people with mental health emergencies. London: Sainsbury Centre for mental health emergen

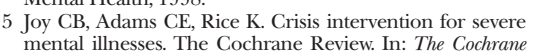
mental illnesses. The Cochrane Review. In: The Cochrane
Library; 1998, Issue 2. Oxford: Update Software; 1998. Library; 1998, Issue
(Updated quarterly.)

\section{Costings were inadequate}

EDITOR-Comparing the costs of home and acute hospital care, Coast et al address a subject of intense interest to NHS managers. ${ }^{1}$ The cost of home care in their study was based on a bottom up analysis, in which use of resources was measured on a patient by patient basis. The cost of hospital care, however, was simply the average cost of inpatient care, which includes the use of operating theatres, etc. Patients for whom both sources of care are a viable option, however, are at the lower end of the intensity range for hospital care. The authors recognise this but address the problem by conducting a sensitivity analysis. They imply that assuming a 
$50 \%$ average cost for these "low intensity" patients is the appropriate extreme case for the sensitivity analysis. This is inappropriate: the unadjusted figures should be at the plausible extreme-indeed, beyond it. They say that only in the extreme case (as they define it) are costs equivocal. But $50 \%$ of the average hospital costs is probably an overestimate of the costs for patients who could be treated in either setting. There is a non-linear relation between the cost of care and its intensity, most care being provided in the early part of patients' admission. ${ }^{2}$

The authors should have been far more temperate in the claim that they made. The study was based on a randomised trial, but in the context of this paper this could easily mislead readers. Patients in the home arm were costed on an individual basis, whereas those in the hospital arm were costed on the aggregate basis, not on the basis of those randomised. It is as if, in a randomised trial of chemotherapy for low grade cancer, the mortality among patients with low grade tumours receiving treatment $\mathrm{A}$ was compared firstly with the mortality among all patients with tumours receiving treatment $B$ and then, arbitrarily, with half the mortality among all patients with tumours receiving treatment $\mathrm{B}$. What is urgently required is a study that uses the same method and rigour to quantify costs in hospital and alternative settings. In the meantime, this paper leaves us no wiser.

R J Lilford Director of research and development Howard Shaw Deputy director of research and development

NHS Executive, Birmingham B16 9PA

rlilford@doh.gov.uk

1 Coast J, Richards SH, Peters TJ, Gunnell DJ, Darlow M-A Pounsford J. Hospital at home or acute hospital care A cost minimisation analysis. BMJ 1998:316:1802-6. (13 June.)

2 Babson JH. Disease costing. Studies in social administration Manchester: Manchester University Press, 1973.

\section{Authors' reply}

EDITOR-Lilford and Shaw provide two main criticisms of the hospital cost data used in our paper. Firstly, they criticise us for using average hospital costs, which include operating costs. This criticism is unjustified. As we specified in the sections on collection and valuation of resource use data in our paper, operating costs were separated from the more general cost elements, defined as specialty overheads and ward and nursing costs. Resource use in terms of both diagnostic tests and operating time was minimal, and hence the resource use for each of these items is not reported in table 4 but is included in table 5 under "other hospital services." Such resource use was minimal because only costs incurred between the randomisation date and the three month follow up were included. Only for the small group of elective patients were general average valuations used for each day of stay after randomisation; again, however, operating costs were excluded from these valuations.

As operating and major diagnostic costs are excluded, we thought that the choices of
$75 \%$ and $50 \%$ of the average cost (that is, the average of specialty overheads plus ward and nursing costs for patients included in the trial) were appropriate values for the sensitivity analysis. In fact, the value of $50 \%$ provides useful information as it is around this point that the decision between the two alternatives becomes more equivocal. We agree, however, that these values are arbitrary, and others may wish to substitute alternative values to recalculate the results. This can easily be done by adjusting the figures in parentheses in table 6 , which show the change from the initial analysis.

Lilford and Shaw state that "patients in the home arm were costed on an individual basis, whereas those in the hospital arm were costed on the aggregate basis, not on the basis of those randomised." This statement is inaccurate. As we stated in the paper, information on hospital resource use was collected on a per patient basis for patients enrolled in the randomised controlled trial just as for hospital at home resource use. In both cases, average valuations were then used to estimate the resource use per patient. The problem to which we suspect Lilford and Shaw are really referring is that the level of detail about hospital resource use available for individual patients was relatively low. We accept this, but the study used the most detailed identification of resource use possible, given the confines of the hospital's routine data systems.

Joanna Coast Lecturer in health economics Suzanne H Richards Research associate Tim J Peters Reader in medical statistics David J Gunnell Senior lecturer in epidemiology and public health medicine

Department of Social Medicine, University of Bristol, Bristol BS8 2PR

jo.coast@bristol.ac.uk

Mary-Anne Darlow Hospital at home team coordinator

Hospital at Home, Downend Clinic, Bristo BS16 5TW

John Pounsford Consultant physician, care of the elderly

Day Hospital, Frenchay Hospital, Bristol BS16 1LE

\section{Acceptability of early discharge, hospital at home schemes}

Treatments that can be safely and acceptably managed at home need to be defined

EDITOR-Richards et al's and Shepperd et al's definitions of what constitutes hospital in the home care are problematic. ${ }^{12}$ Richards et al described hospital in the home as "a generic term, referring to a package of home based nursing and rehabilitation services," while Shepperd et al restricted the eligible groups of patient to patients older than 60 with five broadly defined conditions.

Our concern with these studies is that patients seem to have been selected on the basis of their clinical condition and its burden on the hospital rather than on the basis that their acute hospital based treatment could be appropriately delivered at home. We also wonder whether the selection of conditions for study was determined by the presence of validated research instruments

The appropriate definition of hospital in the home is one in which the patient requires treatment that, without the presence of a hospital in the home delivery system, would otherwise require care in hospital. Substitution of hospital in the home care for acute hospital care is the critical element. In the above papers, the length of stay data showed that the hospital in the home component was additional to the hospital stay rather than a substitute for it.

It is a pity that both papers chose not to consider non-British publications in their discussions, since considerable activity has occurred outside Britain. In Australia hospital in the home programmes provide acute treatment such as intravenous treatment (giving antibiotics, chemotherapy, inotropes, blood products), giving dalteparin for deep venous thrombosis, and complex postoperative wound care..$^{3-5}$ Increasingly, patients are admitted to hospital in the home care directly from the emergency department and are considered inpatients in every sense other than that their care is provided at home. ${ }^{5}$ The hospital retains clinical, fiscal, and legal responsibility for the pharmaceutical input, medical supervision, and nursing care of hospital in the home patients.

Without firm clinical definitions to ensure substitution, cost comparisons are of little value. Most descriptive studies, however, have found cost savings with hospital in the home care if patients are selected carefully. ${ }^{5}$

The challenge for the future of hospital in the home is to determine which types of treatment in which patient groups can be safely, effectively, and acceptably managed at home and which are the best models for delivering quality outcomes. Trials will need to be clear about the nature of the intervention if they are to be helpful in the future.

M Montalto Director, hospital in the home unit Frankston Hospital, Victoria, Australia

M L Grayson Director, hospital in the home programme

Monash Medical Centre, Victoria, Australia

1 Richards SH, Coast J, Gunnell DJ, Peters TJ, Pounsford J, Darlow M-A. Randomised controlled trial comparin effectiveness and acceptability of an early discharge, hospital at home scheme with acute hospital care. BMJ 1998;316:1796-801. (13 June)

2 Shepperd S, Harwood D, Jenkinson C, Gray A, Vessey M, Morgan P Randomised controlled trial com A, Vessey $\mathrm{M}$, Morgan P. Randonised conte tal at home care with inpatient hospital care. 1. Three 90. (13 June.)

3 Montalto M. How safe is hospital in the home care? Med J Aust 1998;168:277-80.

4 Ting S, Ziegenbein R, Eng Gan T, Catalano JV, Monagle P, Silvers J, et al. Dalteparin for deep venous thrombosis: a hospital in the home program. Med J Aust 1998;168:272-6. 5 Grayson ML. Hospital-in-the-home care: is it worth the hassle? Med J Aust 1998;168:262-3.

\section{Care in community hospitals is another} alternative

EDITOR-Two useful papers comparing hospital at home with inpatient hospital care ${ }^{12}$ did not consider another possible lower cost alternative to acute care in a district general hospital-namely, care in a community hospital. 
There are roughly 450 community hospitals in the United Kingdom, with most beds being general practitioner led (data on file, Community Hospitals Association). The recognised roles of such hospitals include general medical care and rehabilitation after falls, strokes, and orthopaedic and general surgery. Seamark et al have reported evidence of good quality care in community hospitals and satisfaction with these hospitals among carers, ${ }^{3}$ and a cost analysis indicated that a community hospital bed cost between a third and a half of a bed in a district general hospital. ${ }^{4}$ The advantages of community hospitals are the proximity to the patients' homes ${ }^{5}$; the low technology environment, which patients find less intimidating; the continuity of care provided by their own general practitioner and primary healthcare team; and hospital staff who are often known to both the patients and the carers.

Given the uncertainties over effectiveness (albeit for certain clinical groups), costs, and probable increased burden on the primary healthcare team, before extensive investment is made in new hospital at home schemes it would be wise to run comparative studies with community hospital facilities; they have a long track record in the type of medicine targeted for hospital at home schemes.

David A Seamark Committee member of Community Hospitals Association

Clare J Seamark Committee member of Community Hospitals Association

Honiton Group Practice, Honiton EX14 8DD

DASEAMARK@msn.com

1 Shepperd S, Harwood D, Jenkinson C, Gray A, Vessey M, Morgan P. Randomised controlled trial comparing hospital at home care with inporient hospital care. I. Thpetal at home care with inpatient hospital care. I. Three month follow

2 Richards SH, Coast J, Gunnell DJ, Peters TJ, Pounsford J, Richards SH, Coast J, Gunnell DJ, Peters TJ, Pounsford J,
Darlow M-A. Randomised controlled trial comparing Darlow M-A. Randomised controlled trial comparing
effectiveness and acceptability of an early discharge, hospieffectiveness and acceptability of an early discharge, hospi-
tal at home scheme with acute hospital care. BMJ 1998;316:1796-801. (13 June.)

3 Seamark DA, Williams S, Hall M, Lawrence CJ, Gilbert J Dying from cancer in community hospitals or a hospice closest lay carers' perceptions. Br J Gen Pract 1998 48:1317-21

4 Tucker H. Financial management and strategy in community hospitals. Report to the Department of Health. London: HACAS, 1991.

5 Seamark DA, Williams S, Hall M, Lawrence CJ, Gilbert J. Palliative terminal cancer care in community hospitals a hospice: a comparative study $B r$ J Gen Prad 1998;48:1312-6

\section{Authors' reply}

EDITOR-Montalto and Grayson raise important points that must be considered when home care is substituted for acute inpatient hospital care. The first point they make concerns the definition of hospital at home. The hospital at home scheme that we evaluated "provided hospital at home as a direct alternative to inpatient care for patients who were clinically stable and did not require immediate access to diagnostic or specialist medical care." Without the presence of hospital at home these patients would have required inpatient hospital care.

As Montalto and Grayson point out, "without firm clinical definitions to ensure substitution, cost comparisons are of little value." We took this argument further by hypothesising that "both outcomes and costs would differ according to diagnosis and age."
We therefore set out to identify suitable groups of patients defined by their clinical condition. After discussions with clinicians and service providers and a review of the published experience of other hospital at home schemes, ${ }^{1}$ we considered five groups of patients to be suitable for the trial. A major issue was to identify groups of patients who were eligible for hospital at home but who would also be recruited in sufficient numbers to provide the study with adequate power.

A second point raised by Montalto and Grayson concerns non-British publications. We did not exclude these. The three articles that they cite were published after our papers were submitted for publication. We do, however, cite the results of a trial conducted in the United States. $^{2}$

Finally, we agree that trials will need to be clear about the nature of the intervention. Indeed, in the discussion of the first paper we write that "one of the most important issues in designing the trial was to define the service provided, and the population to be studied." We did not intend to include all the groups of patients who could receive hospital at home or all the types of treatment that could be delivered by this form of care. We would be delighted to see well designed studies on other groups and treatments.

Sasha Shepperd Research officer, health services research unit

Crispin Jenkinson Deputy director, health services research unit

Diana Harwood Research assistant, health economics research centre

Alastair Gray Director, health economics research centre

Martin Vessey Professor of public health

Division of Public Health and Primary Health Care, University of Oxford, Institute of Health Sciences,

Oxford OX3 7LF

Patrick Morgan Consultant in public health medicine Northamptonshire Health Authority, Northampton NN1 5DN

1 Shepperd S, Iliffe S. Hospital at home compared with in-patient hospital care [review]. In: Bero L, Grilli R, Grimin-patient hospital care [review]. In: Bero L, Grilli R, Grim-
shaw J, Oxman A, eds. The Cochrane Library 1998; Update

2 Hughes SL, Cummings J, Weaver F, Manheim L, Braun B, Conrad K. A randomized trial of the cost effectiveness of VA hospital-based home care for the terminally ill. Healt Serv Res 1992;26:801-17

\section{Role of hospitals in NHS must not be undervalued}

EDITOR-In his clear account of the issues that will need to be addressed if primary care groups are to be introduced successfully into the NHS, Chisholm stated that " $90 \%$ of all episodes of health care take place [in general practice]."1 Although this figure is often used to justify the importance of general practice I have never seen it used with any supporting evidence. I therefore investigated what proportion of episodes of medical care actually take place in general practice.

In the fourth national survey of morbidity in general practice, carried out in 1991-2, patients were found to have consulted their general practitioners an average of about 2.9 times each year. ${ }^{2}$ Hence, in England in
Estimated number and place of episodes of medical care in the NHS, 1992

\begin{tabular}{lcc} 
Place of health care & \multicolumn{1}{c}{$\begin{array}{c}\text { Number of episodes } \\
\text { (millions) }\end{array}$} \\
\hline General practice & & 142.1 \\
\hline Hospital & & 61.2 \\
\hline Day case & 1.8 & \\
\hline Ordinary admission & 7.8 & \\
\hline Outpatient care & 37.5 & \\
\hline $\begin{array}{l}\text { Accident and emergency } \\
\text { department }\end{array}$ & 13.1 \\
\hline Ward attendance & 1.0 \\
\hline
\end{tabular}

1991-2 there were about 142 million consultations with general practitioners (2.9 $\times 49$ million). Data supplied by the Office for National Statistics show that in 1992 about 61 million episodes of medical care occurred in hospitals (table). ${ }^{3}$ Thus, of the estimated total of 203 million episodes of medical care that took place in the NHS in 1992 about 70\% (142 million/203 million) took place in general practice, a substantially lower figure than the frequently quoted $90 \%$. The medical care provided in general practice is important but we must not undervalue the contribution of hospitals to the NHS.

Azeem Majeed Senior lecturer in general practice Division of General Practice, St George's Hospital Medical School, London SW17 0RE

1 Chisholm J. Primary care and the NHS white papers. BMJ 1998;316:1687-8. (6 June.)

2 Royal College of General Practitioners, Office of Population Censuses and Surveys, Department of Health. Morbidity statistics from general practice:fourth national study, 1991-92. London: HMSO, 1995

3 Office for National Statistics. Annual abstract of statistics 1998. London: Stationery Office, 1998.

\section{Combination treatment is rare in patients with rheumatoid arthritis}

EDITOR-The title of Brooks's clinical review article-"Recent advances: rheumatology"-is not appropriate for the contents, which really dealt only with the therapeutics of rheumatoid arthritis rather than advances in rheumatology. ${ }^{1}$ On the topic of disease modifying antirheumatic drugs the author stated that combination treatment was now the rule rather than the exception. This assumption may not be true in many centres in the United Kingdom.

We have completed a review of a random 142 patients with rheumatoid arthritis of four different consultants across two trusts attending outpatient clinics. Only three patients were receiving two disease modifying antirheumatic drugs and none were receiving a combination of three drugs. Even triple combination treatment has been suggested to be superior to single agents. ${ }^{2-4}$ One must, however, approach the research findings of clinical trials with some caution when they are applied to everyday clinical practice. Moreover, the recent encouraging results of combination treatment seem to indicate that the "step down" or "parallel strategy" approach is better than the "step 
up" approach, ${ }^{2}$ which is the likeliest in routine rheumatology practice.

Ours is the fifth largest trust in the United Kingdom, with a large population with rheumatoid arthritis. A sizeable sample from our population shows that an extremely small percentage of patients receive combination treatment; this must suggest that there are limitations (increased toxicity, added costs, and patients' acceptance) in routine application of findings of research and clinical trials. Despite apparent acceptance of combination treatment by rheumatologists abroad $^{3} 4$ I suspect that most district general hospitals and rheumatology centres in the United Kingdom will have only a minority of patients receiving combination treatment, rather than most patients as implied by Brooks. It would be interesting to know the uptake of combination treatment in rheumatology centres in the United Kingdom generally.

Badal Pal Consultant rheumatologist

Hussein Amlesh Specialist registrar in rheumatology Department of Rheumatology, Wythenshawe Hospital, Manchester M23 9LT

Recent advances: rheumatology. BMJ 1998;316:1810-2 (13 June.)

2 Verhoeven AC, Boers M, Tugwell P. Combination therapy in rheumatoid arthritis: updated systematic review. $\mathrm{Br}$ Rheumatol 1998;37:612-9

3 O'Dell J. Combination therapy for rheumatoid arthritis: acparent universal acceptance. Arthritis Rheum 1997;40(suppl):S119.

4 Moreland LW, Kimberley RP, Alarcon GS. European and US rheumatologists agree in triple but not on double or ing early DMARD choice for different types of RA. Arthritis Rheum 1997;40(suppl):S218.

\section{Research is needed to determine how to integrate complementary medicine into the NHS}

EDITOR-Recently there has been much interest in integrating complementary medicine into the NHS. In May the Foundation for Integrated Medicine hosted a conference on integrated health care. Although much debate took place, no definite criteria for integration emerged from the discussions.

To determine which criteria might be useful we questioned healthcare professionals and unit managers from a wide range of clinical disciplines. Subsequently, a questionnaire was designed, which included suggestions made by these professionals and some additional possible criteria generated from published literature and reports. This

The five criteria most frequently chosen by respondents when deciding whether to purchase complementary medicine

\begin{tabular}{lcc} 
Criterion & $\begin{array}{c}\text { No }(\mathbf{\%}) \\
\text { directors of } \\
\text { public health } \\
(\mathbf{n = 9 8 )}\end{array}$ & $\begin{array}{c}\text { No (\%) consortiums } \\
\text { of fundholding } \\
\text { general } \\
\text { practitioners (n=47) }\end{array}$ \\
\hline $\begin{array}{l}\text { Evidence of effectiveness (for example, from randomised controlled trial or systematic } \\
\text { review) }\end{array}$ & $89(91)$ & $37(79)$ \\
\hline Evidence from outcomes studies & $79(81)$ & $37(79)$ \\
\hline Evidence of cost effectiveness & $78(80)$ & $29(62)$ \\
\hline Recognised accreditation procedure and professional standards & $55(56)$ & $28(60)$ \\
\hline Availability of qualified practitioners & $27(28)$ & $17(36)$ \\
\hline
\end{tabular}

resulted in a list of 25 items. In the final questionnaire criteria appeared in alphabetical order, thus according equal weight to each option. The questionnaire was sent to all 122 directors of public health and all 140 primary care fundholding consortiums in the United Kingdom. Recipients were asked to indicate, in no particular order of priority, the five criteria that they considered to be the most important when deciding whether to purchase complementary medicine.

Altogether, 98 directors of public health and 47 individuals each representing one general practice consortium responded (response rates of $80 \%$ and $34 \%$ respectively). The five criteria most frequently selected are shown in the table. There are strong similarities between the two groups. Other data show that the criteria of "patient preference/ pressure/demand/expectation" was selected by only $20 \%$ of respondents in both groups and "anecdotal evidence" by less than $2 \%$

To our knowledge this is the first attempt to establish, in a systematic manner, criteria to inform the discussion of how complementary medicine might actually be integrated into the NHS. Rigorous research ought to precede integration, a notion that seems obvious ${ }^{1}$ but is, at times, forgotten.

E Ernst Head of department

N C Armstrong Research fellow

A R White Research fellow

M H Pittler Research fellow

Department of Complementary Medicine, Schoo of Postgraduate Medicine and Health Sciences, University of Exeter, Exeter EX2 4NT 1 Ernst E. Integrating complementary medicine? J R Soc
Health 1997;117:285-6.

\section{Deaths from low dose paracetamol poisoning} Editorial p 1609

\section{Executive action is needed to change} national guidelines

EDIToR-The lesson of the week by Bridger et al on deaths from low dose paracetamol poisoning was most welcome but probably titled incorrectly. ${ }^{1}$ None of the patients in the cases described took low doses of paracetamol. What did happen was that the current national guidelines for treating patients after poisoning with paracetamol failed to protect these patients.

We suspect that many doctors will have read these cases and dismissed them as poor management, assuming, for example, that the doctors concerned failed to establish the correct timing of the drug ingestion. We fear that complacency will persist with the belief that deaths will not happen if the current guidelines are adhered to properly.

One of the cases was managed in our hospital. The timing and circumstances of the poisoning seemed to be and still do seem to be clear cut. We know the time at which the paracetamol was purchased from a local shop and the time immediately after at which help was sought. These times concur with the history that was given. The concentrations of paracetamol at four hours were $22 \%$ below the national standard treatment line. We believe that the nomogram should allow for a safety margin of $22 \%$.

We agree that there are many possible explanations for our patient's death. Our patient may have been particularly susceptible to paracetamol but equally may have taken a sequential overdose. The key point is that a treatment strategy must allow a margin of safety that allows for some degree of inaccuracy in the history or an individual patient's susceptibility to paracetamol.

We are from the hospital in the south west referred to in the article that has changed its treatment protocol to a lower treatment line. Since making this change in 1994 we have treated around an extra 60 patients each year with acetylcysteine who would not have been treated using the national guidelines. Of these extra patients treated, one third were considered to be at normal risk and two thirds at high risk of hepatotoxicity. We cannot know if any of these patients would otherwise have developed liver failure.

In 1994 we were indebted to Williams for reviewing the modifications that we had made to our local guidelines. These local guidelines are contrary to those in the British National Formulary and of the National Poisons Information Service. We therefore may be vulnerable to medicolegal problems if any patient has a reaction to acetylcysteine. We welcome the article by Bridger et al and strongly advocate that the national guidelines be changed to those now used in Truro. Executive action is clearly needed to review current practice and make appropriate changes to the national recommendations.

John Barnes Clinical director, medicine

Margaret Abban Consultant, medical admissions unit Paul Howarth Consultant in accident and emergency Royal Cornwall Hospital, Truro, Cornwall TR1 3EB

1 Bridger S, Henderson K, Glucksman E, Ellis AJ, Henry JA, Williams R. Deaths from low dose paracetamol poisoning. BMJ 1998;316:1724-5. (6 June.)

\section{Guidelines are under review}

EDITOR-The lesson of the week by Bridger et al is misleadingly titled. ${ }^{1}$ These case reports refer to serum paracetamol concentrations interpreted to be below the standard treatment line, not to low doses. Surely a crucial point is that in treating paracetamol overdoses, patient histories need to be relied on to interpret the clinical significance of serum paracetamol concentrations when 
deciding whether to treat with antidote, and such histories may be unreliable.

The guidelines agreed by the National Poisons Information Service on managing acute paracetamol overdosage advise that patients should be considered at risk of severe liver damage if 24 or more tablets have been ingested; in recognition of the uncertainties of patient histories or any other factors that do not seem to correlate they then say: "If there is doubt about timing or the need for treatment, treat."' The guidelines are currently under review, not only to update the management protocols but also to address the problem of the small number of patients who would benefit from treatment with an antidote but who, for a variety of reasons, do not receive it.

Geoffrey Brandon Director

Paracetamol Information Centre, Suite 413 Butlers Wharf, London SE1 2ND

1 Bridger S, Henderson K, Glucksman E, Ellis AJ, Henry JA, Williams R. Deaths from low dose paracetamol poisoning. BMJ 1998;316:1724-5. (6 June.)

2 Management of acute paracetamol poisoning. Guidelines agreed by the UK National Poisons Information Service (1995). Supplied to accident and emergency centres in the United Kingdom by the Paracetamol Information Centre in collaboration with the British Association for Acciden and Emergency Medicine.

\section{Several issues were not considered in the article}

EDITOR-Several important issues were not addressed by Bridger et al in their lesson of the week on deaths after allegedly low dose paracetamol poisoning. ${ }^{1}$

Firstly, the total dose ingested is important. The current national guidelines state: "Any patient should be considered at risk of severe liver damage if he/she has ingested more than $150 \mathrm{mg}$ paracetamol $/ \mathrm{kg}$ body weight or $12 \mathrm{~g}$ or more in total, whichever is the smaller." ${ }^{2}$ Furthermore, the British National Formulary advises that "as little as 10-15 g of paracetamol may cause severe hepatocellular necrosis." Thus, from the doses ingested each of the four fatal cases should have been considered on presentation to be at high risk of severe liver damage.

Secondly, although they suggested that timing errors were probably to blame for the "non-toxic" serum concentrations of paracetamol in cases 1,3, and 4, Bridger et al did not emphasise the difficulties in assessing patients who present with deliberate self poisoning. Such patients are often uncooperative, manipulative, untruthful, and intoxicated with alcohol or other drugs. A low threshold for treating such patients therefore seems prudent, especially when potentially toxic injury may be attenuated by administration of a specific antidote such as acetylcysteine. This view is clearly advocated in the current national guidelines-namely, "If there is doubt about timing or the need for treatment, treat."

Thirdly, the authors did not mention the uselessness of the current treatment nomogram when paracetamol overdosage has occurred over several hours or more rather than as a single episode. In such cases, treatment with acetylcysteine is generally advisable.
Finally, Bridger et al recommend the adoption of a lower standard treatment line, as widely used in the United States. Interestingly, the Australian guidelines for paracetamol overdosage in adults use the same treatment nomogram as that used in the British guidelines. ${ }^{2}{ }^{3}$ However, these recommendations include the advice that "some experts advocate that ALL cases above this lower line [high risk treatment line ${ }^{2}{ }^{3}$ ] should be treated."

D P McAliskey Senior house officer

Ear, Nose, and Throat Department, Tyrone County Hospital, Omagh, County Tyrone BT79 0AP

1 Bridger S, Henderson K, Glucksman E, Ellis AJ, Henry JA, Williams R. Deaths from low dose paracetamol poisonin BMJ 1998;316:1724-5. (6 June.)

2 British Medical Association, Royal Pharmaceutical Society of Great Britain. Emergency treatment of poisoning. In British National Formulary. No 35. London: BMA, RPS, 1998:20-21.

3 Management of acute paracetamol poisoning. Guidelines agreed by the UK National Poisons Information Service (1995). Supplied to accident and emergency centres in the United Kingdom by the Paracetamol Information Centre in collaboration with the British Association for Accident and Emergency Medicine.

4 Australian Working Group in conjunction with Australasian College for Emergency Medicine. Guidelines for the management of paracetamol overdose in adults (1997). Distributed by SmithKline Beecham International, Consume Healthcare, Ermington, New South Wales, Australia.

\section{Nomogram does not show absolute} concentration for treatment

EDITOR-Bridger et al suggested that all patients presenting with a serum paracetamol concentration $>150 \mathrm{mg} / \mathrm{l}$ should be treated with acetylcysteine, with a treatment threshold of $100 \mathrm{mg} / \mathrm{l}$ for patients with known risk factors for liver disease. Although we agree with this suggestion, we think that the four cases presented do not provide sufficient evidence to support a reduction in the threshold for treatment of paracetamol overdose

For many years the policy in Aberdeen has been to admit all patients with overdose, checking paracetamol concentrations at four hours, or on admission, and again four hours later, thus reducing the effect of timing errors. We immediately start treatment with acetylcysteine in all patients who have ingested more than $150 \mathrm{mg} / \mathrm{kg}$. We also check liver function and prothrombin time to identify those with underlying liver abnormality or early hepatic damage. These patients can then be treated earlier.

As pointed out by the authors, case 2 should have been treated according to the high risk threshold of existing guidelines. Under these same guidelines, cases 3 and 4 should have been treated on the basis of the amount ingested, if not also because the concentrations were close to the treatment line. (We always assume some degree of timing error.)

Case 1 may be an example of what happens when a patient reacts abnormally to paracetamol overdose. Other factors are, however, relevant. She had taken a significant overdose, the timing of which should always be viewed with suspicion. In addition, no mention is made of her weight; therefore, $10 \mathrm{~g}$ could have represented more than $150 \mathrm{mg} / \mathrm{kg}$ for her. With our current practice, deterioration would have been detected earlier and treatment started.

In conclusion, the current guidelines provide a sound basis for managing paracetamol overdose, provided that the nomogram is treated as a guide to risk assessment and not as showing the absolute concentration for treatment.

K S Aujla Specialist registrar in accident and emergency medicine

V M Maclean Specialist registrar in accident and emergency medicine

J R Richardson Specialist registrar in accident and emergency medicine

E M Docherty Specialist registrar in accident and emergency medicine

Accident and Emergency Department, Aberdeen

Royal Infirmary, Aberdeen AB25 2ZD

1 Bridger S, Henderson K, Glucksman E, Ellis AJ, Henry JA Williams R. Deaths from low dose paracetamol poisoning. BMJ 1998;316:1724-5. (6 June.)

\section{If in doubt use the antidote}

EDITOR-Bridger et al suggested changing the treatment line for use of antidotes in patients at standard risk from paracetamol poisoning from that currently recommended, which passes through $200 \mathrm{mg} / \mathrm{l}$ at four hours and $25 \mathrm{mg} / 1$ at 16 hours, to a lower line passing through $150 \mathrm{mg} / \mathrm{l}$ at four hours and $30 \mathrm{mg} / \mathrm{l}$ al 12 hours. ${ }^{1}$ This recommendation is based on the deaths of three patients who were apparently at standard risk and were not treated with an antidote after presenting with concentrations between these two lines. The fourth patient was at high risk of toxicity and would have been treated if current guidelines had been followed.

My colleagues and I recently collected data prospectively on patients presenting with paracetamol poisoning in north east England (43\% of all overdoses). ${ }^{2}$ Extrapolating these data, which reflect the pattern in other parts of the country, ${ }^{34}$ we estimate that around 58000 people take paracetamol overdoses each year in England and Wales. In $9 \%(5500)$ of them the associated paracetamol concentrations are above the currently recommended treatment line, while an additional $6 \%(3500)$ are above the lower line proposed by Bridger et al. The deaths of the three patients in this category show that this group are at some risk. However, the potentially large size of the denominator (which is unknown and depends on the geographical area and the time over which cases have been collected) suggests that the case fatality of this group may be low. They seem to be a small fraction of the patients who die each year of paracetamol poisoning, who may number as many as $200 .{ }^{5}$ It therefore remains uncertain whether their risk of paracetamol toxicity justifies the increased use of resources that would be needed to treat this potentially large group of patients. More information on the occurrence of death and liver failure in this group is needed.

An absolute cut off point between a non-toxic and a toxic paracetamol overdose does not exist. The timing of the blood sample in relation to the overdose is often 
uncertain and some of the differences in susceptibility to paracetamol are not well understood. In judging whether to use an antidote clinicians should always err on the side of caution. When using treatment nomograms they should assume the longest interval between poisoning and blood sampling that is consistent with the history. They should use the lower high risk line if there is any suggestion that a patient might be particularly susceptible-for example, because of alcoholism, use of enzyme inducing drugs, or poor nutrition and cachexia. If in doubt, an antidote should be used.

S H L Thomas Consultant physician

Wolfson Unit of Clinical Pharmacology, Department of Pharmacological Sciences, University of

Newcastle, Newcastle upon Tyne NE2 4HH

1 Bridger S, Henderson K, Glucksman E, Ellis AJ, Henry JA, Williams R. Deaths from low dose paracetamol poisoning. BMJ 1998;316:1724-5. (6 June.)

2 Thomas SHL, Homer JE, Chew K, Connolly J, Dorani B, Bevan L, et al. Paracetamol poisoning in the North East of England: presentation, early management and outcome. Hum Exper Toxicol 1997;16:495-500.

3 Hawton K, Fagg J. Trends in deliberate self poisoning and self injury in Oxford, 1976-90. BMJ 1992;304:1409-11.

4 Bialas MC, Reid PG, Beck P, Lazarus JH, Smith PM Scorer

$\mathrm{RC}$, et al. Changing patterns of self-poisoning in a UK RC, et al. Changing patterns of self-poist
health district. QJ Med 1996;89:893-901.

5 Office of Populion Censes and Surveys. Motality statis-

Ofice of Population Censuses and Surveys. Mortality statis-

tics: cause. London: HMSO, 1994: table 2. (Series DH2
No 20.)

\section{More evidence needed to change} recommendations

Editor-Bridger et al drove home the message of the toxicity of paracetamol overdoses, but they did not comment on whether the patients in cases 3 and 4 might have been helped if they had been given acetylcysteine despite their late presentation.

The authors then recommend that the cut off point for treatment with acetylcysteine should be at a paracetamol concentration of $150 \mathrm{mg} / \mathrm{l}$. It is not clear whether this refers to the concentration at four hours or any other time. Even if this new cut off point were adopted it would have made no difference in case 4. Furthermore, in the study that Bridger et al quote to endorse the lower concentration 1.4\% (3 out of 214) of patients with concentrations below $150 \mathrm{mg} / \mathrm{l}$ developed hepatotoxicity. Does that mean that the treatment concentration should be lowered further?

In these enlightened days of evidence based medicine and cost effectiveness can the authors:

- Calculate the increased number of people who will require treatment at the lower proposed concentration?

- Predict the implications of treatment at the lower concentration on the great number of patients requiring admission, the cost entailed, and the likelihood of any accrued benefit-that is, the numbers needed to treat to save one complication or one death?

If there is no evidence to support the widespread adoption of this policy, should four anecdotal reports in which the management was suboptimal, as the authors acknowledge, be the basis of such a fundamental change? Perhaps not.

D F D'Costa Consultant physician

New Cross Hospital, Wolverhampton WV10 0QP
1 Bridger S, Henderson K, Glucksman E, Ellis AJ, Henry JA, Williams R. Deaths from low dose paracetamol poisoning. BMJ 1998;316:1724-5. (6 June.)

2 Smilkstein MJ, Knapp GL, Kulig KW, Rumack BH. Efficac of oral acetylcysteine in the treatment of acetaminophen overdose. N Engl J Med 1988;319:1557-62.

Lower threshold has probably not overburdened hospital services in Gloucester

EDITOR-I was heartened to read that Bridger et al have recommended a reduction in the threshold for treatment with acetylcysteine in cases of paracetamol poisoning.

We have been using the lower threshold recommended by Bridger et al at this hospital since 1995. Two points may help to persuade others to adopt the lower threshold.

Firstly, immediately before the lower threshold was implemented a review of cases of paracetamol poisoning over six months (an average of one case per day presenting to the accident and emergency department) showed that only one additional admission would have resulted had the lower threshold been in place during these six months. This is reassuring to those who fear overburdening of already stretched inpatient services.

Secondly, having been asked to give evidence at an independent inquiry into one of the deaths reviewed in the case series by Bridger et al, I was astonished and disappointed to hear the inquiry panel criticise the junior doctor who followed the then existing guidelines and did not treat with acetylcysteine since the patient's paracetamol concentration was significantly below the treatment line. It seems that the lesson revealed in the BMJ in 1998 was expected to have been intuitively grasped by a junior doctor several years before.

M G Cameron Consultant in accident and emergency medicine

Gloucestershire Royal Hospital, Gloucester

GL1 3NN

1 Bridger S, Henderson K, Glucksman E, Ellis AJ, Henry JA, Williams R. Deaths from low dose paracetamol poisoning. BMJ 1998;316:1724-5. (6 June.)

Use of oral methionine for overdose below threshold for acetylcysteine

EDITOR-Bridger et al suggested reducing the threshold for treatment with acetylcysteine after a paracetamol overdose to reduce the risk of hepatotoxicity. We would like to draw attention to oral methionine treatment, an effective antidote for paracetamol poisoning. ${ }^{2-4}$

Oral activated charcoal is often prescribed to patients who have taken paracetamol alone, and this prohibits the use of oral methionine. ${ }^{3}$ We treat patients who repeatedly use paracetamol to harm themselves. They often experience charcoal treatment as punishing and humiliating because the solution is difficult and unpleasant to swallow and stains clothes; this adds to their emotional distress. Were they to be allergic to intravenous acetylcysteine it would also seriously impair the absorption of oral methionine. In addition, patients may not be able to say when they took the overdose, partly because of their distress and partly because they may have taken paracetamol over several hours.

We immediately start treatment with oral methionine $(2.5 \mathrm{~g})$ before measuring blood paracetamol concentrations. We transfer all patients who do not have simple paracetamol poisoning to the local accident and emergency department (dose $>150 \mathrm{mg} / \mathrm{kg}$, body mass index $<17.5 \mathrm{~kg} / \mathrm{m}^{2}$, positive for HIV infection, alcohol misuse, prescribed drugs that induce liver enzymes). We initially manage patients with simple paracetamol poisoning in the psychiatric ward, where we measure blood concentrations. Three further doses of $2.5 \mathrm{~g}$ methionine are given every four hours if concentrations are $>200 \mathrm{mg} /$ four hours after ingestion (or the equivalent at later times), the overdose started under 10 hours before, and patients have no significant nausea and are not vomiting. We always err on the side of caution in continuing methionine treatment

Apart from occasional nausea and vomiting, our patients find this management acceptable and humane. We have used this conservative policy for the past three years without encountering any associated untoward events. Because of the problems identified by Bridger et al, we now plan to give methionine to all patients with simple paracetamol poisoning whatever their blood concentrations. We suggest that all patients presenting to accident and emergency departments with simple paracetamol poisoning should be prescribed oral methionine on presentation and that oral charcoal should not be used at all. Thus treatment with intravenous acetylcysteine could be started if necessary according to the recommendations of Bridger et al. ${ }^{1}$ Otherwise, oral methionine could be continued as an outpatient under the supervision of a responsible adult, who could also provide emotional support and encourage patients to return for psychiatric follow up.

Ben Wright Specialist registrar in psychiatr

Michael Crowe Consultant psychiatrist

Crisis Recovery Unit, Bethlem and Maudsley NHS

Trust, London SE5 8AZ

1 Bridger S, Henderson K, Glucksman E, Ellis AJ, Henry JA Williams R. Deaths from low dose paracetamol poisoning. BMJ 1998:316:1794-5. (6 Jow dose

2 Janes J, Routledge PA Recent developments in the Janes J, Routledge PA. Recent developments in the
management of paracetamol (acetaminophen) poisoning. management of paracetan

3 Flanagan RJ, Meredith TJ. Use of N-acetylcysteine in cliniFlanagan RJ, Meredith TJ. Use of N-acetylcyst
cal toxicology. Am J Med 1991;91(3C):131-9S.

cal toxicology. Am J Med 1991;91(3C):131-9S.
Vale JA, Meredith TJ, Goulding R. Treatment of

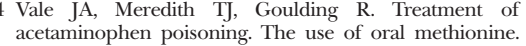
Arch Intern Med 1981;141:394-6.

\section{Authors' reply}

EDITOR-We thank the correspondents for their constructive comments. With respect to the assertion of Barnes et al and Brandon that our lesson of the week was misleadingly titled, we would say that our title, "Fatal paracetamol overdose in patients not treated with an antidote" was submitted to the editorial process. It is a pity if this detracted from the intended message and led correspondents to concentrate on the issue of drug dosage.

Brandon, McAliskey, and Aujla et al emphasised the importance of total dosage 
ingested and referred to the current national guidelines. ${ }^{1}$ However, in clinical practice, the decision to treat with an antidote is universally determined by a single blood paracetamol concentration in conjunction with the type and timing of the overdose and the presence or absence of risk factors. As such, we agree with Barnes et al and Thomas that the current clinical guidelines failed for three of our four patients. The large studies analysing mortality after paracetamol overdose have not shown any correlation between the amount of paracetamol allegedly ingested and the blood concentration found. ${ }^{2}$ The principle of adopting a lower threshold for treatment using a nomogram which joins a paracetamol concentration of $150 \mathrm{mg} / \mathrm{l}$ at four hours with a value of $30 \mathrm{mg} / \mathrm{l}$ at 12 hours has already been accepted by some of the respondents. In answer to D'Costa's assertion that such a nomogram would have made no difference in the treatment of case 4 , this patient's concentration of $122 \mathrm{mg} / \mathrm{l}$ was measured six hours after ingestion.

Our audit findings, like those of Cameron, indicate that implementation of the lower threshold for a hospital accident and emergency department seeing 75000 patients a year would result in the admission of one extra patient a month. Thomas suggests that this modification could lead to the treatment of an extra 3500 patients a year in England and Wales. However, we are aware that many physicians already err on the side of caution and treat a substantial number of these patients. Consequently the "denominator" may not be as large as Thomas assumes. The four cases we reported were referred over two years to one regional liver unit. Even if no other cases occurred in England and Wales during this time and if Thomas's extrapolated figures are accurate, then the case fatality of this group could be one in 1000 or more. In view of the tragedy of a preventable death, the high medical and economic costs of treating patients with preventable liver failure, and the proved efficacy and safety of acetylcysteine or methionine, we reiterate our recommendation to treat all patients presenting with blood paracetamol concentrations greater than $150 \mathrm{mg} / \mathrm{l}$ at four hours.

S Bridger Clinical research fellow

Department of Medicine, King's College School of Medicine, London SE5 9PJ

$\mathbf{K}$ Henderson Consultant in accident and emergency medicine

A J Ellis Consultant physician, Institute of Liver Studies E Glucksman Consultant in accident and emergency medicine

Roger Williams Professor of hepatology, Institute of Liver Studies

King's College Hospital, London SE5 9RS

John Henry Professor

Accident and Emergency Department, St Mary's Hospital, London W2 1NY

1 Management of acute paracetamol poisoning. Guidelines agreed by the UK National Poisons Information Service (1995). Supplied to accident and emergency centres in the United Kingdom by the Paracetamol Information Centre in collaboration with the British Association for Accident and Emergency Medicine.

2 Read RB, Tredger JM, Williams R. Analysis of factors responsible for continuing mortality after paracetamo overdose. Hum Toxicol 1986;5:201-6.

\section{Limitation of over the counter sales of paracetamol}

Packaging policy is unlikely to achieve its aim of reducing suicide

EdiTor-New regulations to limit the availability of aspirin and paracetamol came into effect on 16 September. ${ }^{1}$ The number of tablets or capsules per pack has been limited to 16 in supermarkets and 32 in pharmacies, although multiple packs can be bought Pharmacists can provide up to 100 tablets at their discretion for patients with chronic conditions, but greater amounts now require a prescription. Supermarkets may also sell 100 tablets, albeit in packs of 16 .

The health of the nation target was a $15 \%$ reduction in overall suicide rates by $2000 .{ }^{2}$ These packaging regulations aspire to reduce the incidence of deliberate and accidental overdose, but we believe that their effect will be limited. No single intervention was found to reduce suicide. ${ }^{3}$ The authors commented that measures to reduce the quantity of medicines available over the counter should be evaluated but suggested that only interventions of proved effectiveness should be introduced. ${ }^{3}$ Currently there is no such evidence available to justify these major changes.

Thirty two paracetamol tablets is sufficient to commit suicide, and this amount is available in one container from pharmacies and in two from supermarkets. An adult requires only $12 \mathrm{~g}$ to achieve a toxic dose. ${ }^{4}$ On one day we purchased eight packs of paracetamol from four different supermarkets, obtaining 128 tablets within half an hour without any difficulty or questioning. Clearly the regulations prevent no obstacle to the acquisition of lethal doses.

Since the implementation of the new regulations the cost of paracetamol over the counter has roughly doubled. This extra cost is partly due to the new packaging and has been passed on directly to consumers. The same considerations apply to aspirin, including the low dose preparation $(75 \mathrm{mg})$. Patients entitled to free prescriptions may be more likely to approach their general practitioner to obtain these drugs because of this price increase. This will generate more work for general practitioners.

We are all encouraged to practice evidence based medicine, with rational prescribing being one result of such an approach. The same principles should apply to policy making. The health of the nation strategy is full of good intentions, ${ }^{5}$ but more effective policies are needed for suicide to be reduced. These changes represent laudable aspirations but are a paternalistic folly. We believe that they are unlikely to succeed and will only inconvenience the vast majority of people, who use these drugs appropriately and responsibly, and add to the workload of general practitioners and pharmacists.

Mike Cranney General practitioner

Julie Cranney Health visitor (retired)

St Helens, Merseyside WA10 5HP

Helen Stubbs Assistant pharmaceutical adviser Liverpool Health Authority, Liverpool L3 6AL Conflict of interest: None.
1 Committee on Safety of Medicines, Medicines Control Agency. Paracetamol and aspirin. Current Problems in Pharmacovigilance 1997;23:9. (September.)

2 Secretary of State for Health. The health of the nation. A strategy for health in England. London: HMSO, 1992. (Cm 1986.)

3 Gunnell D, Frankel S. Prevention of suicide: aspirations and evidence. $B M J$ 1994;308:1227-33.

Thomas SHL. Management of poisoming. 3rd ed. Newcastle: Newcastle Poisons Centre, 1997 .

5 Mooney G, Healey A. Strategy full of good intentions. BMJ 1991:303:1119-20.

\section{Restriction to $16 \mathrm{~g}$ will not prevent} overdose and is unhelpful for patients with chronic disease

Editor-From September 1998 over the counter sales of paracetamol have been limited to 32 tablets. Notice of this restriction and the reasoning behind it have not been widely publicised since the Medicines Control Agency sought comments in 1996. I often recommend (and take) regular paracetamol to enhance the efficacy and reduce the side effects of non-steroidal antiinflammatory agents. Since the recommended initial treatment for degenerative arthritis is $2-4 \mathrm{~g}$ paracetamol daily, ${ }^{1}$ those affected now have painful walks to the pharmacist twice weekly to buy the same drug at more than double the price. Although the human and financial cost of paracetamol poisoning is high, these restrictions are not only inconvenient but an unfair financial burden on the millions of people who adhere to the recommended doses and derive enormous therapeutic benefit from the drug. The success of rationing will largely depend on deterring those likely to take overdoses, but self poisoning is usually impulsive and seldom entails a planned purchase. ${ }^{2}$ Additionally, selective restriction of one drug will lead to an alternative being chosen or to the more familiar scenario of "overdose cocktails," which are more dangerous because of multiple drug toxicity and interaction. Although paracetamol overdose remains common, most episodes result in subtoxic plasma concentrations and few clinical sequelae, ${ }^{3}$ and since as little as $10-15 \mathrm{~g}$ of paracetamol may be lethal, this token restriction of $16 \mathrm{~g}$ seems unhelpful. What should be addressed is the prevention of repetitive overdoses, the increase in poisoning by prescribed drugs, ${ }^{4}$ and the adverse effect that cases of trivial overdose have on the ability to provide acute medical care to those who may be in greater need.

Nigel I Jowett Consultant physician Department of Medicine, Withybush Genera Hospital, Haverfordwest, Pembrokeshire SA61 2PZ

1 Eccles M, Freemantle N, Mason J for the North of England NSAID Guideline Development Group. North of England evidence based guideline development project: summary guideline for non-steroidal anti-inflammatory drugs versus basic analgesia in treating the pain of degenerative arthritis. BMJ 1998;317:526-30. (22 August.)

2 Hawton K, Fagg J. Trends in deliberate self-poisoning an self injury in Oxford, 1976-90. BMJ 1992;304:1409-11.

3 Thomas SH, Horner JE, Chew K, Connolly J, Dorani B, Bevan L, et al. Paracetamol poisoning in the North East of England: presentation, early management and outcome. Hum Exper Toxicol 1997;16:495-500.

4 Bialas MC, Reid PG, Beck P, Lazarus JH, Smith PM, Scorer

$\mathrm{RC}$, et al. Changing patterns of self-poisoning in a UK health district. OJ Med 1996;89:893-901. 


\section{National patient groups are a resource underutilised by GPs}

EDITOR-Although Meryn is right to identify the need for improvements in the ability of doctors to communicate with patients, his proposal that communication skills should be included as a mandatory element of the medical school curriculum offers only a partial solution. ${ }^{1}$

However accomplished a communicator a doctor may be, three factors conspire to inhibit effective communication with patients. The first is time: typically doctors are able to spend only seven minutes with an NHS patient. The second is fallible short term memory: it is widely accepted that few patients remember more than the first and last things doctors tell them. The third is generalism: general practitioners-the doctors most people see-are, by definition, generalists, and what they do not know they cannot communicate.

National patient organisations are a resource that is underutilised by doctors. In addition to the research they fund and the role they play in educating the public, they are an excellent source of specialist information, advice, and support. They make available as much time as may be needed. They offer written information as well as support via helplines. And they have detailed knowledge of the conditions in which they specialise and of the treatment and management of those conditions. For the vast majority of these organisations, the quality and consistency of the information they provide is assured by a medical or scientific committee consisting of health professionals who are experts in their fields.

There is substantial research evidence to show the clinical benefits of membership in patient organisations. Doctors who do not already do so could help their patients and ease their own burdens by directing patients and carers to appropriate patient support groups.

Peter Lapsley Chief executive

National Eczema Society and the Skin Care Campaign, London NW1 1BU

1 Meryn S. Improving doctor-patient communication. $B M$ J 1998;316:1922. (27 June.)

\section{Postnatal depression}

\section{Postnatal depression is not being missed} in primary care

EDITOR-In their review of postnatal depression Cooper and Murray comment that depression is often missed by primary care teams. ${ }^{1}$ There are several reasons why this might be the case, even though a reliable tool (the Edinburgh postnatal depression scale) has been available for detecting its

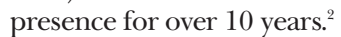

When the Edinburgh postnatal depression scale has been used to detect postnatal depression, health visitors have used various strategies to help women, with varying degrees of success. ${ }^{23}$ Factors that influence the process of screening and caring for women with postnatal depression include health visitors' workload and their willingness to use the Edinburgh postnatal depression scale ${ }^{3}$ and the readiness of women to be labelled as patients with depression, to accept an intervention by a health visitor, ${ }^{2-4}$ or to be referred for further care. ${ }^{23}$ There is still uncertainty about when to use the Edinburgh postnatal depression scale, where to set the threshold for the purposes of screening, ${ }^{2 .}$ and how to prioritise patients and determine which intervention is likely to be the most appropriate and effective. ${ }^{2-4}$

Watson et al showed that women with postnatal depression could be classified into as many as six categories. ${ }^{5}$ Cooper and Murray's comments on the aetiology of postnatal depression confirm their findings. McIntosh has recommended that a personalised women-centred approach is the most appropriate and more likely to be successful than reliance on just drug treatment or counselling. ${ }^{4}$

Cooper and Murray highlight the impact of postnatal depression on child development and behaviour and comment that this can be a consequence of communication problems. The impact of postnatal depression on a mother's ability to cope, which is a difficult concept to measure and evaluate, may be the most important factor affecting infant development and behaviour. In my general practice there are women who are not depressed according to a rating scale such as the Edinburgh postnatal depression scale but are not coping; others, with depression, seem to the general practitioners and health visitors to be coping. I wonder whether an approach to new mothers that focuses on their ability to cope and the resources available to help them will be more fruitful than the recommendation to diagnose depression. Clinicians in primary care teams need not feel guilty about comments from the secondary sector that they are missing patients.

J P Richards Professor of primary care School of Nursing and Midwifery, University of Glamorgan, Pontypridd, Cardiff CF37 1DL

1 Cooper PJ, Murray L. Postnatal depression. BM 1998:316:1884-6. (20 June.)

Richards JP. Postnatal depression: a review of recent literature. Br J Gen Pract 1990;40:472-6.

3 Gerrard J, Holden J, Elliott SA, McKenzie P, McKenzie J, Cox JL. A trainer's perspective of an innovative teaching Gox JL A train's pective of an ingovalive teaching progranne Nurs 1993:18:1825-32. 4 McIntosh J. Postpartum depression: women's help-seeking
behaviour and perceptions of cause. J Adv Nurs 1993;18:178-84.

5 Watson JP, Elliott SA, Rugg AJ, Brough DI. Psychiatric disorder in pregnancy and the first postnatal year. $\mathrm{Br}$ Psychiatry 1984;144:453-62.

\section{Biology mustn't be excluded}

EDITOR-By stating that "there is little evidence to support a biological basis to postpartum depression," Cooper and Murray as psychologists risk the accusation of taking just as partisan an approach to the subject as biological psychiatrists sometimes do. ${ }^{1}$ We are a species of supremely socialised primates who have evolved awareness of our inner drives and thoughts, so all human behaviour and illness, including mental illness, shares biological, psychological, and social factors that are so tightly overlapped and interwoven that to divide them in order to exclude some becomes futile. Would Cooper and Murray say, for instance, that there was no biological basis to the attachment behaviour of Harlow's rhesus monkeys or that there was no biology at the root of Bowlby's observations of human infant attachment?

Childbirth and early parenthood are profound psychosocial stressors, and these aspects must be prominent in any aetiological formulation of postpartum depression. But to see postpartum depression as arising only from these aspects would run counter to the impression of many psychiatrists. They believe that, rather than being a discrete homogeneous disorder, it lies in the middle of a spectrum of severity that culminates in postpartum psychosis, which clearly includes a biological factor in its aetiology.

The biopsychosocial approach to treatment of postpartum depression should use any therapeutic tool available, including pharmacological and other biological treatments, precisely because all current treatments are inadequate. The article states that drug treatment is no better than, and perhaps less welcome than, psychological treatment, but the fact that it is effective at all should be promoted rather than minimised. The alternative in clinical practice in many areas is a wait of several months for anything more than the most basic psychological treatments.

The detrimental effect of maternal depression on infant development was admirably described in the article and deserves the widest possible readership. This knowledge should spur us to our best multidisciplinary efforts for the many women and children who suffer from the adverse mental and physical consequences of childbirth.

Peter Talbot Research fellow in mental health Holywell Hospital, Antrim, Northern Ireland

peter.talbot@dial.pipex.com

1 Cooper PJ, Murray L. Postnatal depression. BMJ 1998;316:1884-6. (20 June.)

\section{National registry is also needed for neurological implants}

EDITOR-Three public health doctors propose in a letter that a registry of hip implants should be established. ${ }^{1}$ This causes me to relate the experience that I have had in attempting to establish a national registry for neurological implants (electrical stimulators and drug delivery systems). Having personally identified that an electrical stimulator model (produced by one company) had an incidence of defects of over $50 \%$, I eventually persuaded the Medical Devices Agency to establish a national registry for neuroimplants. Compliance was a problem as several different specialties use the implants. After two and a half years the agency stopped supporting this registry in spite of suggestions of how the problem of compliance could be overcome-for exam- 
ple, by offering a small payment for compliance, as was done for neuroshunts.

My concern about the risks undertaken by patients and the expense to the health budget (some of these implants cost up to $£ 8000$ ) has been ignored even when taken right up to the health minister. Leaving the problem of monitoring defects in equipment to the manufacturers seems to be common.

A recent failure of another batch of neurostimulators, with another manufacturer involved, received an equal amount of disinterest. I am led to believe that in the United States registering of implants is obligatory, and I see such registration as being inevitable in Britain.

John Miles Senior consultant neurosurgeon Walton Centre for Neurology and Neurosurgery NHS Trust, Liverpool L9 7Lj

1 Riordan P, Bickler G, Lyons C. Lessons of a hip failure. BMJ 1998;316:1985. (27 June.)

\section{Inequalities in health}

Report on inequalities in health did give priority for steps to be tackled

EDITOR-The editorial by Davey Smith et $\mathrm{al}^{1}$ devoted to the Report of the Independent Inquiry into Inequalities in Health ${ }^{2}$ is welcome in many ways but gives a misleading account of some aspects. The authors give the impression that the 39 recommendations were presented without any priority being given. In fact, we selected three clear priorities, which are the focus of our first three recommendations. These are paraphrased in the synopsis as follows:

"There are three areas which we regard as crucial:

- all policies likely to have an impact on health should be evaluated in terms of their impact on health inequalities

- a high priority should be given to the health of families with children

- further steps should be taken to reduce income inequalities and improve the living standards of poor households."

The editorial also states that "the key fact that inequalities in health follow closely inequalities in wealth" is underestimated. On the contrary, in addition to nominating the reduction of income inequalities as a priority we note on page 33 of the text that "without a shift of resources to the less well off, both in and out of work, little will be accomplished in terms of a reduction of health inequalities by addressing particular 'downstream' influences."

In line with our remit to identify priority areas for policy development we assembled and assessed a large volume of evidence on each major area. It is important that each recommendation should be read in conjunction with the accompanying text. This gives a summary of the scale and nature of the inequality at which the recommendation is directed, a review of the evidence on how that inequality might be reduced, and an assessment of the expected benefit from the recommended action.
In respect of the recommendations relating to the prevention of suicide and the reduction of the fear of violence, which Davey Smith et al find "too vague to be useful," several specific suggestions as to how these goals could be achieved are summarised respectively on pages 54 and 55 (crime and violence) and 78 and 107 (suicide).

We believe that this report has assembled in one volume, which includes over 500 references, a wide ranging and up to date body of evidence on actions to tackle inequalities in health. It would be a pity if those who read the $B M$ fs editorial were discouraged from making use of it

Donald Acheson Chairman

Independent Inquiry into Inequalities in Health, London SE1 8UG

1 Davey Smith G, Morris JN, Shaw M. The independen inquiry into inequalities in health. BMJ 1998;317:1465-6. (28 November.)

2 Report of the independent inquiry into inequalities in health London: Stationery Office, 1998.

\section{Studies of inequality in health need} careful interpretation

EDITOR-The papers by Davey Smith et al and Kunst et al show that the relation between relative deprivation and health is likely to be cause specific and to vary according to geographical region and across the life course. ${ }^{2}$ Contextual variation and change across time are the lynch pins of a dynamic approach to inequality in health, but our understanding of these social processes is often limited by the constraints of imprecise tools of measurement

Davey Smith et al used father's social class as a measure of social factors acting in early life on cause specific mortality in men aged 35-64 in 1970-3. These men lived through a period of major social change, with the oldest seeing large improvements in standards of living so that by the $1970 \mathrm{~s}$ relative deprivation rather than absolute poverty was associated with premature death. In their lifetime the burden of premature death shifted from infant mortality from infectious and respiratory diseases to lung cancer and heart disease in middle and late middle age; they all lived through the second world war and the associated changes in lifestyle and diet. These circumstances make it difficult to imagine how father's social class can capture the specific influences of social factors in childhood on adult mortality, whatever statistical adjustments have been made. Conclusions drawn from such evidence necessarily remain speculative.

Kunst et al analysed geographical (country) variation in the relation between occupational class and cause specific mortality for men aged 45-59 in 11 western European countries in 1980-9. Despite observing that for some causes of death, particularly ischaemic heart disease, rates of mortality were not stratified by occupational class in all countries, they used all cause mortality to conclude that the mortality advantage of higher socioeconomic groups occurred in all countries. But the value of cause specific analysis is precisely that it reveals differences where none are initially seen. Further anomalies in the picture presented by all cause mortality are shown by comparing cause specific mortality of men and women across time. ${ }^{34}$

Exceptions to the general rule of poorer health for less advantaged groups present a challenge for conventional models of inequality in health. They also provide the opportunity to develop methods that can illuminate questions of if and when, as well as how and why, powerful social influences such as cultural mores, health related behaviours, and social roles combine with relative poverty or affluence to create and maintain inequality in health.

Deborah Baker Senior research fellow

Division of Child Health, Department of Clinical Medicine, University of Bristol, Bristol BS8 1TQ

Raymond Illsley Visiting professor

Department of Social Policy, University of Bath, Bath

1 Davey Smith G, Hart C, Blane D, Hole D. Advers socioeconomic conditions in childhood and cause specific adult mortality: prospective observational study. BMJ 1998;316:1631-5. (30 May.)

2 Kunst AE, Groenhof F, Mackenbach JP, EU Working Group on Socioeconomic Inequalities in Health. Occupational class and cause specific mortality in middle aged men in 11 European countries: comparison of population based studies. BMJ 1998;316:1636-42. (30 May.)

3 Baker D. Poverty and disease: a postcard from the edge. JR Soc Med 1995;88:127-9.

Illsley R, Baker D. Inequality in health: adapting the theory to fit the facts. Bath: University of Bath, Bath Social Policy Papers, 1997.

\section{The Bristol affair}

\section{Surgeons were treated unjustly}

Editon-James Garrett claims credit for exposing "the medical scandal of the century" and accuses me of wishing to shoot the messenger. ${ }^{2} \mathrm{He}$ may come to regret this claim for there is a growing perception that the actual scandal lies in the unjust way in which the surgeons have been treated.

Garrett believes that he reported the case fairly in his Dispatches programme and in the many documentaries that followed. But how often did he report the fact that the 50 or so patients subject to the General Medical Council's inquiry represented less than $4 \%$ of the surgeon's paediatric practice in 1990-5? Did he report that a disproportionate number of the infants under scrutiny were at particularly high risk? Has he reported the president's tribute to the surgeons' commitment, hard work, and best of intentions or the legal assessor's statement that they were of unimpeachable character? Has he given publicity to the fact that the original charges of clinical and technical incompetence had been dismissed, or that the principal remaining charge rested on a fine professional judgment as to whether the surgeons should have stopped operating two or three patients earlier than they did?

Garrett asserts that the surgeons' failure to issue any writs proves that the media reports could not have been misleading or inaccurate. This is not true. My information is that both surgeons wished to issue writs but were advised in the interests of their 
patients to maintain a dignified silence and to reserve their comments for any professional inquiry that might ensue.

Garrett also states that the failure of the surgeons to appeal to the Privy Council against the GMC's findings must show that they accepted the fairness of the verdict. Nothing could be further from the truth Both surgeons were keen to appeal. However, the central issue at stake was that of the professional judgment of the GMC. Although strong arguments were available to the surgeons, the Privy Council was known to review only points of law and had not been known to overturn decisions based on the GMC's professional judgment. This was indeed the reason why I advocated the urgent need to revise the terms under which appeals against GMC's verdicts should in future be heard.

Peter M Dunn Emeritus professor of perinatal medicine and child health

University of Bristol, Southmead Hospital, Bristol BS10 5NB

1 Garrett J. The Bristol affair: "Dispatches" programme was painstakingly researched and did not attract writ for defamation. BMJ 1998;317:1592-3. (5 December.)

2 Dunn PM. The Wisheart affair: paediatric cardiologica services in Bristol, 1990-5. BMJ 1998;317:1144-5. (24 October.)

**:Dunn responds here to only one of the letters published last week in response to his original article because it was posted on our website, more than a week ago. The other letters to which he might want to respond were posted only in the middle of last week. Those interested in following the debate on the Bristol case as it happens should look at the rapid responses on our website (www.bmj.com). Readers can view all responses to the article by going to the original Dunn article and clicking on the words "Electronic responses to this article" in the box in the top right hand corner of the screen. The debate after all articles can of course be followed in the same way.-Editor, $B M J$

\section{Advice to authors}

We prefer to receive all responses electronically, sent either directly to our website or to the editorial office as email or on a disk. Processing your letter will be delayed unless it arrives in an electronic form.

We are now posting all direct submissions to our website within 72 hours of receipt and our intention is to post all other electronic submissions there as well. All responses will be eligible for publication in the paper journal.

Responses should be under 400 words and relate to articles published in the preceding month. They should include $\leqslant 5$ references, in the Vancouver style, including one to the BMJ article to which they relate. We welcome illustrations.

Please supply each author's current appointment and full address, and a phone or fax number or email address for the corresponding author. We ask authors to declare any competing interest.

Letters will be edited and may be shortened.

www.bmj.com

letters@bmj.com

\section{GMC clarifies readers'} misunderstandings

EDITOR-After almost eight months of the most careful consideration of events at Bristol Royal Infirmary, the General Medical Council's professional conduct committee found three doctors guilty of serious professional misconduct. ${ }^{1}$ One of them, Dr John Roylance, has exercised his right of appeal to the judicial committee of the Privy Council; in advance of that appeal it would be inappropriate for me to be drawn into the debate being conducted in the BMJ. Clearly, however, some of those who have commented recently are unfamiliar with the professional conduct committee's procedures or with the facts, and I wish to try to correct the misunderstandings that may consequently arise.

Inquiries conducted by the professional conduct committee are governed by statutory rules approved by the Privy Council and designed to ensure fairness and compliance with the rule of law. There is always a legal assessor-a lawyer of at least 10 years' standing, normally a QC. The legal assessor, who sits with the committee in public and during its deliberations in camera, has explicit statutory duties. In the words of the legal assessor who sat throughout the Bristol inquiry, he is there "to assist ... where questions of relevance or admissibility or general fairness may arise." Any advice given to the committee during its deliberations in camera must be repeated in public.

On 10 December 1997 defence counsel made an application that the whole committee should discharge itself on the grounds that there was a real danger of bias in the determination of the case; or, alternatively, that the chairman-the president of the GMC-should discharge himself from the committee. Extensive legal submissions followed, from both defence counsel and counsel for the GMC, at the close of which the legal assessor offered his advice to the committee. Having received the legal assessor's advice, the committee deliberated and rejected the application that it or the chairman should step down. Given that this issue may be raised in Dr Roylance's appeal, it would be improper for me to expand further at this stage.

It has been suggested that the charges against Dr Roylance should have been considered after those against the two surgeons. The structure of the inquiry was determined by the preliminary proceedings committee, not the professional conduct committee, and was known to the defence for six months in advance. The rules specifically provide for one inquiry to be held into charges against two or more practitioners. No objection was taken by any of the doctors to the approach adopted.

In summary, the professional conduct committee's inquiry was held in public; all the doctors were represented by QCs; the committee was advised by a legal assessor, a senior QC; and all three doctors had a right of appeal to the judicial committee of the Privy Council. Many doc- tors and others to whom I have spoken share the view that these matters should now be left to the law lords, who will rule in due course.

Finlay Scott Chief executive

General Medical Council, London W1N 6JE fscott@gmc-uk.org

1 The Bristol affair [letters]. BMJ 1998;317:1592-3. (5 December.)

\section{Undergraduate education must include improving health of minority ethnic communities}

EDITOR-Lloyd's editorial discussed the prevalence and treatment of mental illness in the community among different ethnic groups, ${ }^{1}$ following a survey by the Policy Studies Institute. ${ }^{2}$ He mentioned the government's commitment to improving the health of black and minority ethnic communities and the formation of health authority action zones. We believe that a vital component of assisting the development of appropriate and culturally sensitive services, and consequently improving health, is to raise awareness of these issues in the undergraduate curriculum.

In collaboration with Birmingham Health Authority and University of Birmingham Healthcare Trust, the University of Birmingham Medical School is undertaking a project (funded by the Department of Health) to make medical education more responsive to community diversity, in particular ethnic diversity. Our aim is to develop an integrated strand of teaching through all years of the curriculum, operating in both community and hospital based specialties.

The possibility of giving students a wider and more representative experience while they study in Birmingham has been highlighted in the preliminary findings of our project. As part of the behavioural science course, students visit a local family a minimum of six times over 12 months. A survey of first year students conducted this year showed that only $15(13 \%)$ of 118 families could have been described as coming from a minority ethnic background. In 1991 a quarter of the population of Birmingham defined itself as being from a minority ethnic group. ${ }^{3}$ Feedback of these figures to the local general practitioner tutors may help ensure a broader experience for students next year.

Rhian Loudon Clinical research fellow

Sheila Greenfield Senior lecturer

Department of General Practice, University of Birmingham, Birmingham B15 2TT

1 Lloyd K. Ethnicity, social inequality, and mental illness. BMJ 1998;316:1763-70. (13 June.)

2 Nazroo JY. Ethnicity and mental health: findings from a community survey. London: Policy Studies Institute, 1997. 3 Office of Population Censuses and Surveys. 1991 census. London: OPCS, 1993

Rapid responses
$\begin{aligned} & \text { Rapid responses submitted directly to our } \\ & \text { website are available on www.bmj.com }\end{aligned}$

